\title{
Expression of activities of two 20a-hydroxysteroid dehydrogenase isozymes in rat corpora lutea
}

\author{
H-H. Seong ${ }^{1}$, K. Shiota ${ }^{2}$, K. Noda ${ }^{2}$, A. Ogura ${ }^{3}$, T. Asano ${ }^{3}$ and \\ M. Takahashi ${ }^{1 *}$ \\ Departments of ${ }^{1}$ Veterinary Physiology and ${ }^{2}$ Cellular Biochemistry, Veterinary Medical Science, \\ The University of Tokyo, Tokyo 113, Japan; and ${ }^{3}$ Department of Veterinary Medicine, National \\ Institute of Health, Tokyo 141, Japan
}

\begin{abstract}
Summary. The rat ovary contains two isozymes of $20 \alpha$-hydroxysteroid dehydrogenase (HSD-1 and HSD-2). In this study, the expression of activity of each isozyme was investigated in ovaries that contained a single generation of corpora lutea during pseudopregnancy. This condition was induced by cervical stimulation in rats that had been rendered anovulatory by housing them in a continuously lit environment. The total activity of cytosolic $20 \alpha$-HSD was lower in the ovaries of these pseudopregnant rats than in ovaries containing multiple generations of corpora lutea. In normal pseudopregnancy, HSD-1 activity was low on days 5 and 9 and increased markedly on day 15, whereas HSD-2 was lower than HSD-1 and did not vary throughout pseudopregnancy. However, on days 5 and 9 of continuous-light pseudopregnancy, low activity of HSD-1 only was detected; by day 15, HSD-1 activity had increased sixfold and HSD-2 activity could be detected.

Immunohistochemical methods using a specific antibody recognizing both HSD-1 and HSD- 2 revealed that the number of $20 \alpha$-HSD-positive luteal cells increased by day 15. Thus, the increase in total enzyme activity and appearance of HSD-2 activity observed at late pseudopregnancy was accompanied by an increase in the number of 20 $\alpha$-HSD-positive luteal cells.
\end{abstract}

Keywords: 20a-hydroxysteroid dehydrogenase; pseudopregnancy; corpus luteum; rat

\section{Introduction}

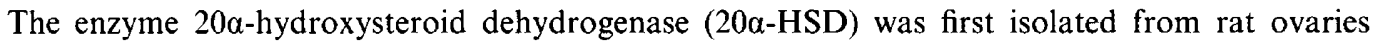
(Wiest, 1959; Wiest \& Wilcox, 1961) and plays a key role in converting progesterone to a biologi-

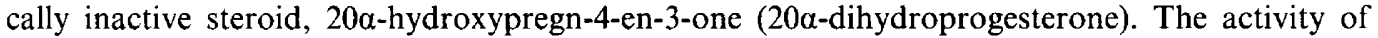
20a-HSD is associated with luteal regression (Wiest et al., 1968) and is known to increase at the termination of pseudopregnancy and pregnancy (Kuhn \& Briley, 1970). Cytosolic 20 $\alpha$-HSD is derived from both luteal and non-luteal ovarian tissue, activity in the former being 3-5 times higher than that in the latter at the end of pseudopregnancy (Matsuda et al., 1990).

We have purified $20 \alpha$-HSD and found two distinct $20 \alpha$-HSD molecules designated HSD-1 and HSD-2, which have different electric charges, Michaelis constants and substrate specificities (Noda et al., 1991). The expression of these activities differed during the course of pseudopregnancy: the ovarian HSD-1 concentration was constant whereas the concentration of HSD-2 gradually decreased with the advance of pseudopregnancy (Shiota et al., 1988). These data were obtained using rat ovaries that carried multiple generations of corpora lutea, and thus further study was needed to determine which component of ovarian tissue is responsible for this change in enzymatic 
activities. In this study, the expression of each type of $20 \alpha$-HSD was investigated in pseudopregnant rats possessing a single generation of corpora lutea.

\section{Materials and Methods}

\section{Reagents}

DEAE Toyopearl 650 S was obtained from Toso Co. Ltd, Tokyo, Japan. Nicotinamide adenine dinucleotide phosphate (NADP) and 20 $\alpha$-dihydroprogesterone were purchased from the Sigma Chemical Co., St Louis, MO, USA. The protein assay reagent was obtained from Bio-Rad Laboratories, Richmond, CA, USA. Phenylmethanesulphonyl fluoride, leupeptin and all other chemicals were purchased from Wako Pure Chemicals (Japan) and all were of analytical grade.

\section{Animals}

Female Wistar-Imamichi rats (body weight $200-250 \mathrm{~g}, 10-12$ weeks of age) were housed under controlled lighting conditions of $14 \mathrm{~h}$ light: $10 \mathrm{~h}$ dark (lights on $05: 00-19: 00 \mathrm{~h}$; normal condition) and at a temperature of $22 \cdot 0^{\circ} \mathrm{C}$. Vaginal smears were taken daily. Only animals that had shown regular 4-day oestrous cycles for more than two cycles were used. Some animals were rendered pseudopregnant by cervical stimulation applied between 18:00 and 19:00 $\mathrm{h}$ on the pro-oestrous day. Some other regularly cycling rats under a normal light regimen were transferred to an isolated room in which continuous lighting was supplied. Animals that had shown continual vaginal epithelium cornification for more than 15 days under continuous lighting were used, and ovulation and subsequent pseudopregnancy was induced by cervical stimulation between 18:00 and 19:00 h (Takahashi et al., 1977). The day after stimulation were designated day 0 of pseudopregnancy. Rats induced to be pseudopregnant in continuous light were kept under continuous light until they were killed.

\section{Tissue sampling and collection of blood}

Pseudopregnant animals were killed by decapitation between $11: 00$ and $13: 00 \mathrm{~h}$ on days 5,9 and 15 of pseudopregnancy. Cycling rats at dioestrus (day after metoestrus) were killed between 18:00 and 20:00 h. The ovaries from pseudopregnant rats were removed, freed from adherent tissues and stored at $-80^{\circ} \mathrm{C}$ until use. Of the ovaries from dioestrous rats, corpora lutea were identified macroscopically and as many as possible were enucleated. Thus, the ovarian tissue from dioestrous rats was separated into either luteal tissue or non-luteal tissue.

Blood samples were collected throughout the period of pseudopregnancy, allowed to clot at room temperature for $2 \mathrm{~h}$ and centrifuged at $1500 \mathrm{~g}$ for $15 \mathrm{~min}$. The sera thus obtained were stored at $-20^{\circ} \mathrm{C}$ until the hormone assay.

\section{Preparation of rat ovarian cytosol}

Each frozen ovarian tissue was weighed and homogenized in 20 volumes of potassium phosphate buffer ( $5 \mathrm{mmol}$ $1^{-1}, \mathrm{pH} 7 \cdot 0$ ) containing 1 mmol EDTA $\mathrm{l}^{-1}, 1 \mathrm{mmol}$ dithiothreitol $1^{-1}$ and $10 \%$ glycerol. Protease inhibitors, $1 \mathrm{mmol}$ phenylmethanesulfonyl fluoride $\mathrm{l}^{-1}$ and $50 \mathrm{mg}$ leupeptin $\mathrm{ml}^{-1}$, were added immediately before homogenization. The homogenate was centrifuged at $105000 \mathrm{~g}$ for $90 \mathrm{~min}$. The final supernatant was used as the cytosol fraction. All procedures were performed at $4^{\circ} \mathrm{C}$.

\section{Measurement of activity of $20 \alpha$-hydroxysteroid dehydrogenase}

Activity of $20 \alpha-\mathrm{HSD}$ was measured by the method of Wiest et al. (1968) with a few modifications. The assay medium was Tris- $\mathrm{HCl}$ buffer solution $\left(0 \cdot 1 \mathrm{~mol}^{-1}, \mathrm{pH} 8 \cdot 0\right)$ containing $30 \mu \mathrm{mol} 20 \alpha$-dihydroprogesterone $1^{-1}$, $300 \mu \mathrm{mol}$ NADP $1^{-1}, 1 \mathrm{mmol}$ EDTA $1^{-1}, 5 \mathrm{mmol}$ dithiothreitol $\mathrm{l}^{-1}$, and $3 \%$ ethanol for steroid solubilization; dithiothreitol and NADP were added immediately before use; $500 \mu \mathrm{l}$ of the assay medium was warmed to $37^{\circ} \mathrm{C}$ in a special microcuvette $(0.7 \mathrm{ml})$. The enzyme reaction was initiated by introducing a $25 \mu \mathrm{l}$ sample into the cuvette with rapid mixing. The temperature during the assay was maintained at $37^{\circ} \mathrm{C}$. Initial velocities were followed spectrophotometrically at $340 \mathrm{~nm}$ for 3 min with a Hitachi U-2000 Spectrophotometer (a molar absorbance of 6220 at $340 \mathrm{~nm}$ was used to calculate NADPH concentrations). One unit of enzyme activity was defined as the amount that could reduce $1 \mu \mathrm{mol}$ NADP $\min ^{-1}$ at $37^{\circ} \mathrm{C}$.

\section{Separation of HSD-I and HSD-2}

The ovarian cytosol sample was applied to a DEAE-Toyopearl $(0.7 \times 6.7 \mathrm{~cm}, 650 \mathrm{~S})$ anion-exchange column on a high-performance liquid chromatography system (Waters model 650: Waters, Bedford, MA). Chromatography was 
performed at $1 \mathrm{ml} \mathrm{min}^{-1}$ using $5 \mathrm{mmol}$ potassium phosphate buffer solution $1^{-1}(\mathrm{pH} 7 \cdot 0)$ containing 1 mmol EDTA $1^{-1}, 1 \mathrm{mmol}$ dithiothreitol $1^{-1}$ and $10 \%$ glycerol (buffer $\mathrm{A}$ ) and eluted with a linear gradient of increasing $\mathrm{KCl}$ concentration in buffer A. Eluates were fractionated into $500 \mu 1$ per tube and the enzyme activity was measured as already described. The HSD-1 eluted between fractions 13 and 17, and HSD-2 between fractions 21 and 22 (Noda et al., 1991).

\section{Steroid hormone assays}

Concentration of serum $20 \alpha$-dihydroprogesterone was determined by radioimmunoassay using specific antibodies raised in our laboratory as described by Matsuyama et al. (1990).

\section{Histological studies by indirect immunofluorescence}

The antibody against 20 $\alpha$-HSD was generated in 6-week-old ICR mice by repeated intradermal injections of the purified HSD-2 preparation emulsified in complete Freund's adjuvant. Serum was collected and purified into an IgG fraction by protein A Sepharose chromatography. The reactivity of the antibody was examined against the purified preparations of HSD-1 and HSD-2 by the enzyme-linked immunosorbent assay, using anti-mouse IgG labelled with horseradish peroxide $o$-phenylenediamine. At the dilution of 1:100 or 1:1000 of the antiserum, the absorbances at $490 \mathrm{~nm}$ were 0.43 or 0.06 for HSD- 1 and 0.45 or 0.055 for HSD-2, respectively, indicating that this antibody showed almost equal reactivity towards HSD-I and -2, probably because of the similarity in the amino acid sequence of these isozymes.

Indirect immunofluorescence histology was performed on ovarian sections from continuous-light pseudopregnant rats. Sections, $5 \mu \mathrm{m}$ thick, were prepared from specimens frozen in liquid nitrogen.

The sections were first exposed to the antibody at $1: 80$ dilution for $20 \mathrm{~h}$ at $4^{\circ} \mathrm{C}$ and then rinsed with phosphate buffer solution and incubated for $4 \mathrm{~h}$ at room temperature with fluorescein-conjugated rabbit anti-mouse IgG (MBS, Japan) $(1: 30, v / v)$. After further rinsing with phosphate buffer solution, they were mounted in $50 \%$ glycerol in phosphate buffer solution. The specimens were then observed with a Nikon fluorescence microscope.

\section{Protein assay}

Protein was quantified by the method of Bradford (1976) using the Bio-Rad protein assay (Bio-Rad Laboratories, Richmond, CA, USA) with bovine serum albumin as a standard.

\section{Statistical analysis}

Duncan's multiple-range test was used for statistical evaluation of the results. Differences at $P<0.05$ were considered to be statistically significant.

\section{Results}

\section{Activity of 20 $\alpha$-HSD in luteal and non-luteal tissue}

In cycling rats on the day of dioestrus, activities of both isozymes of $20 \alpha$-HSD were detected in luteal and non-luteal tissue (Table 1), but the activity of each was much higher in luteal than in non-luteal tissue. The total activities of $20 \alpha-H S D$ in the unfractionated and fractionated samples were almost the same, suggesting removal of some unknown inhibitor during fractionation.

\section{Activity of 20 $\alpha$-HSD in the cytosol of ovarian cells of pseudopregnant rats}

The $20 \alpha$-HSD activity (the samples were not fractionated into HSD-1 and -2) of cytosol of ovarian cells was assayed on day 5,9 or 15 (Fig. 1). In normal pseudopregnant rats, the activity was high on days 5 and 9 and increased further on day 15. In pseudopregnant rats in continuous light, activities on days 5 and 9 were one-sixth of those in normal rats. Although the activity increased on day 15 , it was only half that of normal rats. Concentrations of $20 \alpha$-dihydroprogesterone from day 4 to 12 were similar in normal and continuous-light rats, being highest on days 14 and 15 (Fig. 2). 


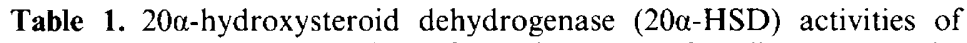
the luteal and non-luteal tissue from the ovary of cycling rats on the day of dioestrus before and after DEAE-Toyopearl anion exchange chromatography

\begin{tabular}{lcccc}
\hline & \multicolumn{4}{c}{$20 \alpha$-HSD activity } \\
\cline { 2 - 5 } & & \multicolumn{3}{c}{ Fractionated } \\
\cline { 2 - 5 } Tissue & Unfractionated & HSD-1 & HSD-2 & Total \\
\hline Luteal & $102 \cdot 1 \pm 19 \cdot 8^{\text {a }}$ & $53 \cdot 5 \pm 28 \cdot 6$ & $54 \cdot 2 \pm 9 \cdot 9$ & $108 \cdot 4 \pm 15 \cdot 5$ \\
Non-luteal & $20.5 \pm 1.9^{*}$ & $11.9 \pm 0.7^{*}$ & $6 \cdot 3 \pm 1 \cdot 3^{*}$ & $18 \cdot 1 \pm 2 \cdot 5^{*}$ \\
\hline
\end{tabular}

$20 \alpha$-HSD activity is expressed as nmol NADPH $\min ^{-1}$ per pair of ovaries.

${ }^{a}$ Each value represents the mean \pm SEM for six animals.

*Significantly different from corresponding luteal tissue $(P<0.05)$.

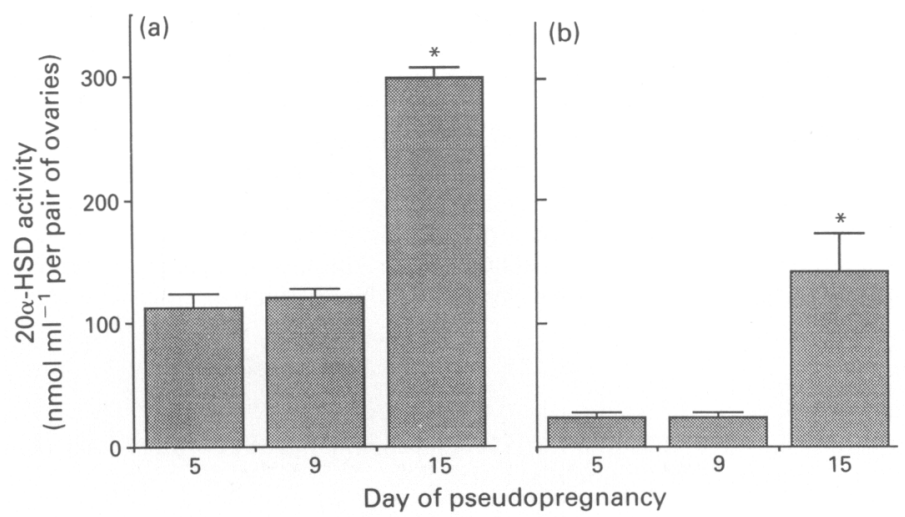

Fig. 1. Activity of ovarian cytosolic $20 \alpha$-hydroxysteroid dehydrogenase (20a-HSD) in pseudopregnant rats in (a) normal or (b) continuous light conditions. Each column and vertical bar represents the mean \pm SEM for 3-5 animals. The enzyme activity was expressed as mmol NADPH $\min ^{-1} \mathrm{ml}^{-1}$, with 1 unit of activity defined as the amount that can induce $1 \mathrm{mmol}$ NADPH min ${ }^{-1} \mathrm{ml}^{-1}$ at $37^{\circ} \mathrm{C}$. ${ }^{*}$ Significantly different from corresponding values at days 5 and 9 of pseudopregnancy $(P<0.05)$.

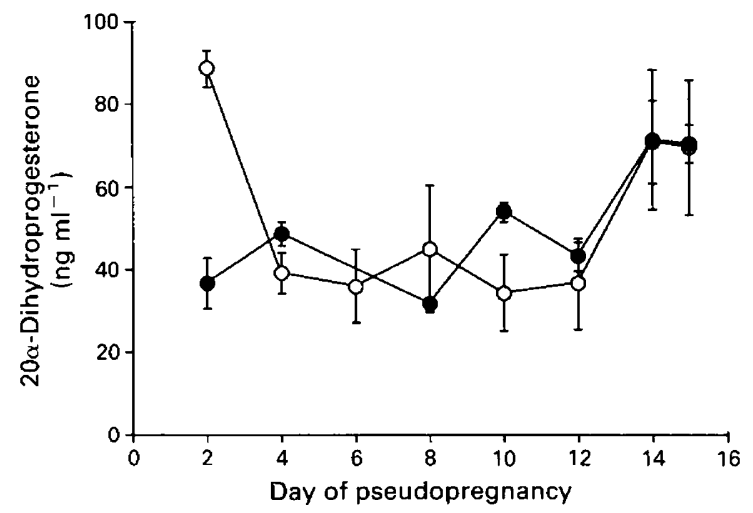

Fig. 2. Concentration of $20 \alpha$-dihydroprogesterone in serum of pseudopregnant rats in normal (O) or continuous $(0)$ light conditions. The day after cervical stimulation was designated day 0 of pseudopregnancy. Each column and vertical bar represents the mean \pm SEM for $3-5$ animals. 


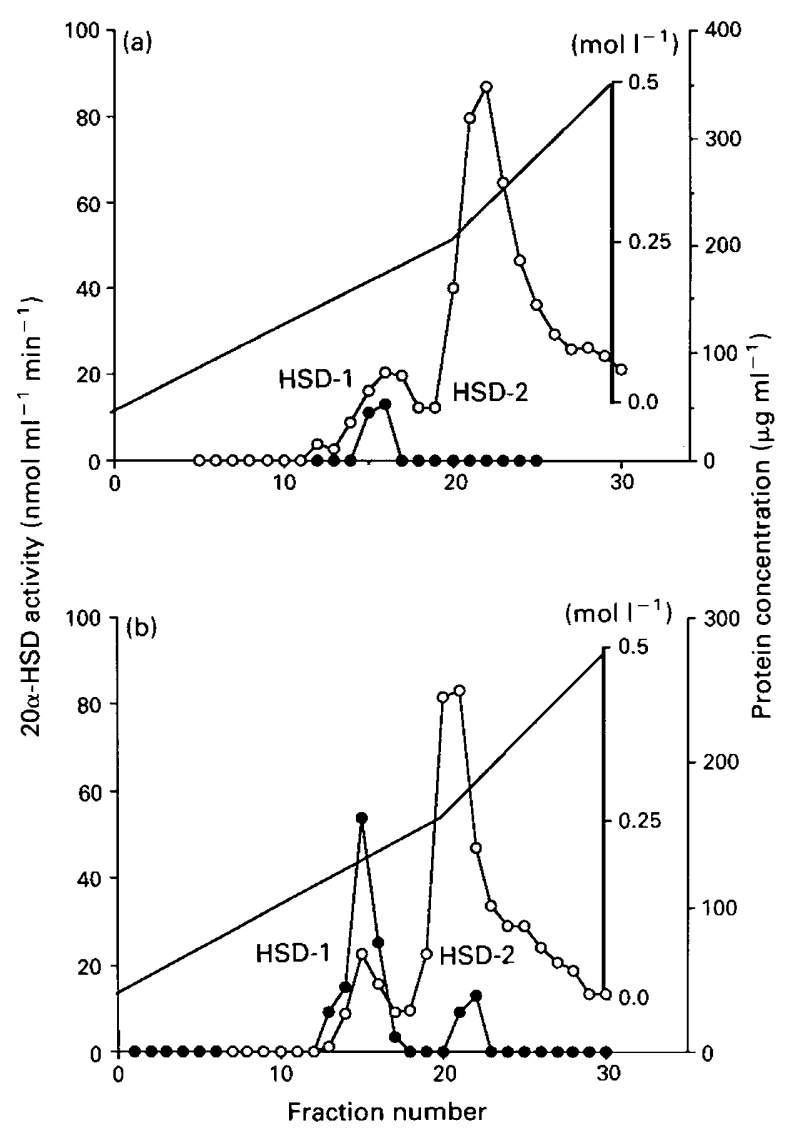

Fig. 3. High-performance liquid chromatography profiles of activities of $20 \alpha$-hydroxysteroid dehydrogenase $(O)$ and protein concentration $(O)$ in ovaries of rats on a preparative DEAEToyopearl anion-exchange column $\left(0.7 \times 6.7 \mathrm{~cm}^{2}, 650 \mathrm{~S}\right)$ using (a) day 9 and (b) day 15 pseudopregnant rats in continuous light conditions. Chromatography was performed at $1 \mathrm{ml}$ $\min ^{-1}$ with a linear gradient of $\mathrm{KCl}(-)$ : for $0-50 \% 0.5 \mathrm{~mol} \mathrm{KCl}^{-1}$ for $10 \mathrm{~min}, 50-100 \%$ for $5 \mathrm{~min}$ and $100 \%$ of $0.5 \mathrm{~mol} \mathrm{KCl} \mathrm{l}^{-1}$ for $5 \mathrm{~min}$. Activity of $20 \alpha$-hydroxysteroid dehydrogenase was assayed using $20 \alpha$-dihydroprogesterone as a substrate.

On day 9 in rats in continuous light only HSD-1 activity was observed (Fig. 3a) but, on day 15 (Fig. 3b), HSD-2 activity was detected together with an increase in HSD-1 activity. In normal rats, activity of HSD-1 increased towards the end of pseudopregnancy and activity of HSD-2 decreased, in accordance with a previous report (Noda et al., 1992). In rats exposed to continuous light, activity of HSD-1 also increased towards the end of pseudopregnancy although values were lower than those in normal rats, and HSD-2 was detected only on day 15 (Fig. 4).

\section{Distribution of anti-20 $\alpha$-HSD-positive cells in the corpus luteum}

Immunoreactive $20 \alpha$-HSD was localized in the luteal cells from pseudopregnant rats in continuous light conditions on day 9 (Fig. 5a). Within one corpus luteum, luteal cells staining positively and negatively with anti-20 $\alpha$-HSD were observed. Both types of cell, with an increased proportion of those staining positively, were found in pseudopregnant rats in continuous-light conditions on day 15, but the follicle was not stained (Fig. 5b). 


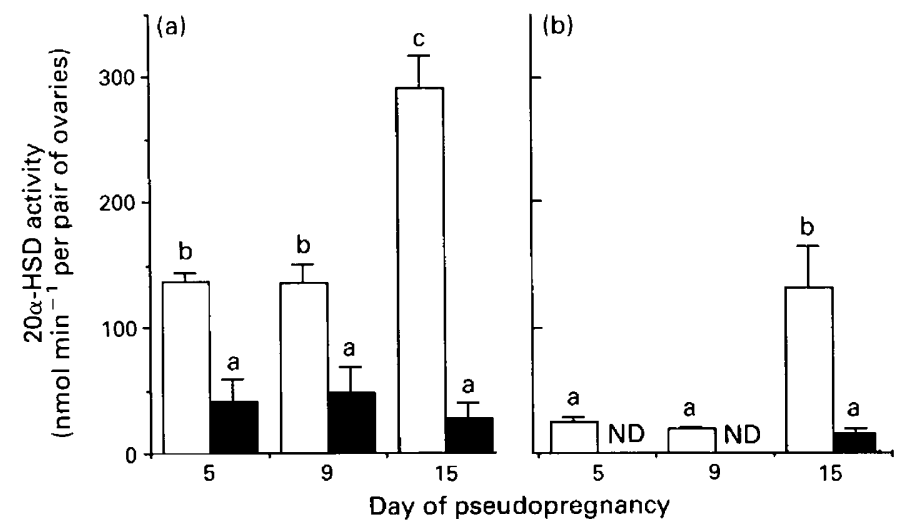

Fig. 4. Changes in activities of $20 \alpha$-hydroxysteroid dehydrogenase- 1 ( $\square$ ) and $20 \alpha$-hydroxysteroid dehydrogenase- $2(\boldsymbol{\square})$ in ovaries of pseudopregnant rats in (a) rats in normal light conditions or (b) rats in conditions of continuous light. Activities were measured after ovarian cytosolic samples had been subjected to DEAE-Toyopearl anion-exchange chromatography on highperformance liquid chromatography. ND: not detected. Each column and vertical bar represents the mean \pm SEM for 3-5 animals. Within a measurement, means with different superscripts differ significantly $(P<0 \cdot 05)$.

\section{Discussion}

The activities of HSD-1 and HSD-2 were investigated by biochemical and immunohistochemical methods in the ovary of pseudopregnant rats kept in conditions of continuous light. The ovary of pseudopregnant rats kept in continuous light carries only a single generation of corpora lutea (Takahashi \& Suzuki 1969; Murakami et al., 1982). We confirmed our previous results that in

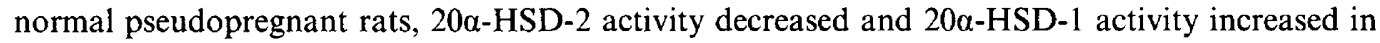
late pseudopregnancy (Noda et al., 1992). In a similar way to normal rats, HSD-1 activity was dominant in rats exposed to continuous light throughout the period of pseudopregnancy. The activity of $20 \alpha$-HSD-2 was detected only at late pseudopregnancy. Changes in activity of each isozyme during the course of pseudopregnancy therefore differed between normal rats and rats in continuous-light conditions. This difference is due to the different cellular components of these ovaries: the ovary from normal pseudopregnant rats contains multiple generations of corpora lutea, whereas that of continuous-light pseudopregnant rats contains a single generation. These results therefore indicate that (i) corpora lutea of older generations contribute more to whole ovarian $20 \alpha$-HSD activity, (ii) newly formed corpora lutea contain only $20 \alpha$-HSD-1 activity, and (iii) old corpora lutea express activities of each HSD isozyme as shown in the luteal tissue of cycling rats on the day of dioestrus where only degenerating old corpora lutea exist.

Ovarian 20a-HSD has been studied histologically in normally cycling rats using the substrateenzyme reaction (Wiest et al., 1963, 1968; Pupkin et al., 1966). Enzyme activity was detected in fresh corpora lutea in the afternoon of the day of metoestrus and more intensely on the next day

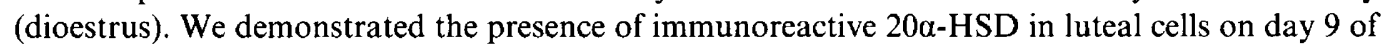
pseudopregnancy and the reactivity increased towards the end of pseudopregnancy with a concomitant increase in the number of $20 \alpha$-HSD-positive cells. The increase in $20 \alpha$-HSD activity identified in this study seems to be related to an increase in the number of $20 \alpha-H S D$-positive cells. The $20 \alpha$-dihydroprogesterone levels after day 4 of pseudopregnancy were virtually identical in normal rats and in rats kept in continuous light, although the total activity of $20 \alpha-H S D$ in the whole ovary of pseudopregnant rats kept in continuous light was less than half that of normal pseudopregnant rats. The main site of metabolism of progesterone to $20 \alpha$-dihydroprogesterone must be the luteal cells of newly formed corpora lutea. Where there is $20 \alpha-\mathrm{HSD}$ activity in ovarian tissue other than 

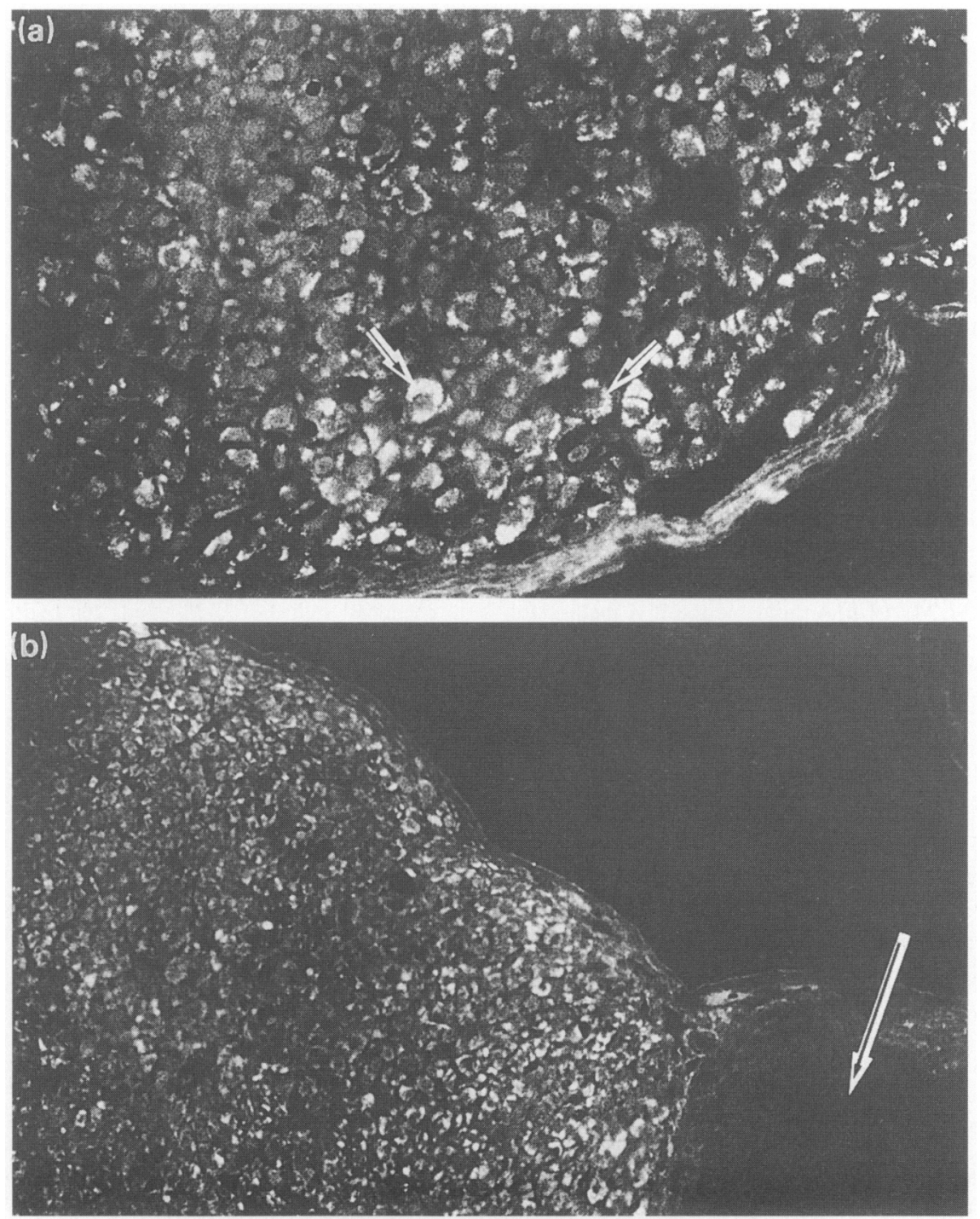

Fig. 5. Sections ( $5 \mu \mathrm{m}$ thick) of ovarian tissue from a normal pseudopregnant rat on (a) day $9(\times 189)$ and $($ b) day $15(\times 95)$. The immunoreactivity with anti-20a-hydroxysteroid dehydrogenase antibody is demonstrated by the indirect immunofluorescence. Note granular fluorescence (arrows) in the cytoplasm of luteal cells (a) and intensely stained luteal cells (b). The follicle (arrow) was not stained (b).

the corpus luteum, a much lower contribution to progesterone catabolism would be made owing to a lower local concentration of the substrate (progesterone) than in luteal cells where progesterone is synthesized. Furthermore, HSD-1 was found to be the major subtype responsible for progesterone catabolism. Activity of HSD-2 may not be involved in the luteolytic process at all, since its activity was minimal even at day 15 of pseudopregnancy.

We previously found that the enzymatic activity increased when the sample was passed through a DEAE column (Noda $e$ t al., 1991), which suggests that there is a $20 \alpha$-HSD-regulatory substance which alters enzymatic activity. In the present study, a slight increase was seen after DEAE chromatography in ovarian cytosolic preparations from dioestrous rats. The role of $20 \alpha-\mathrm{HSD}$ 
activity in the residual tissue of the ovary or aged corpora lutea cannot be wholly explained by the discussion above. We previously found multiple types of $20 \alpha-\mathrm{HSD}$ in spontaneous neoplasms and suggested a possible role for a survival factor in tumour cells, which protects them from the cytotoxic action of progesterone by metabolizing it to the inactive hormone $20 \alpha$-dihydroprogesterone (Shiota et al., 1991).

Progesterone is known to be cytotoxic to several types of cell (Fuks \& Weinstein, 1979). During normal oestrous cycles, corpora lutea begin to express $20 \alpha$-HSD activity $3 \cdot 5$ days after ovulation and thus activity is maintained for at least 9 days when luteal cells are phagocytosed by macrophages (Pupkin et al., 1966). The activity of $20 \alpha-$ HSD may be related to a survival mechanism of those luteal cells remaining in the ovary.

We are deeply grateful to the Imamichi Institute for Animal Reproduction for providing the animals and to D. B. Douglas for reading the manuscript. This study was supported in part by a Grant-in-aid for Developmental Scientific Research from the Ministry of Education, Science and Culture, Japan.

\section{References}

Bradford, M. M. (1976) A rapid and sensitive method for quantitation of microgram quantities of protein utilizing the principle of protein-dye binding. Analytical Biochemistry 72, 248-254.

Fuks, A.S. \& Weinstein, Y. (1979) 20a-hydroxysteroid dehydrogenase (20a-HSD) activity in New Zealand mice $\mathrm{T}$ lymphocytes and bone marrow cells: effect of age, sex, and castration. Journal of Immunology 123, 1266-1271.

Kuhn, N.J. \& Briley, M.S. (1970) The roles of pregn-5-ene$3 \beta, 20 \alpha$-diol and $20 \alpha$-hydroxysteroid dehydrogenase in the control of progesterone synthesis preceding parturition and lactogenesis in the rat. Biochemical Journal 117, 193-201.

Matsuda, J., Noda, K., Shiota, K. \& Takahashi, M. (1990) Participation of ovarian 20a-hydroxysteroid dehydrogenase in luteotrophic and luteolytic processes during rat pseudopregnancy. Journal of Reproduction and Fertility 88, 467-474.

Matsuyama, S., Shiota, K. \& Takahashi, M. (1990) Possible role of transforming growth factor- $\beta$ as a mediator of luteotropic action of prolactin in rat luteal cell cultures. Endocrinology 127, 1561-1567.

Murakami, N., Takahashi, M., Suzuki, Y. \& Homma, K. (1982) Responsiveness of dispersed rat luteal cells to luteinizing hormone and PRL during the estrous cycle and early pseudopregnancy. Endocrinology 111, $500-508$.

Noda, K., Shiota, K. \& Takahashi, M. (1991) Purification and characterization of rat ovarian 20a-hydroxysteroid dehydrogenase. Biochimica et Biophysica Acta 1079, 112-118.

Noda, K., Seong, H-H., Shiota, K. \& Takahashi, M. (1992) Changes of two kinds of 20a-hydroxysteroid dehydrogenase during luteal phase in the rat. Journal of Reproduction and Development 38, 49-53.

Pupkin, M., Bratt, H., Weisz, J., Lloyd, C.W. \& Balogh, K. (1966) Dehydrogenase in rat ovary. 1. A histo- chemical study of 5-3 $\beta$ - and $20 \alpha$-hydroxysteroid dehydrogenase and enzymes of carbohydrate oxidation during the estrous cycle. Endocrinology 79, 316-327.

Shiota, K., Noda, K. \& Takahashi, M. (1988) Purification of $20 \alpha$-hydroxysteroid dehydrogenase and its significance in reproductive activity. In the 22nd $N I B B$ Conference: The Molecular Basis of Communication within Cells, Okazaki, Japan, February, 1989 (Abstract 14) Ed. Y. Nagahama. National Institute of Basic Biology, Japan.

Shiota K., Sasaki, N., Hattori, N., Miura, R., Hasegawa, T., Jin, X.G., Noda, K. \& Takahashi, M. (1991) Cytosolic 20a-hydroxysteroid dehydrogenase activity in spontaneous neoplasms in the dog and cat. Journal of Veterinary Medical Science 53, 549-552.

Takahashi, M. \& Suzuki, Y. (1969) The dependency of the rat estrous cycle on the daily alteration of light and dark. Endocrinologia Japonica 16, 87-102.

Takahashi, M., Ford, J.J., Yoshinaga, K. \& Greep, R.O. (1977) Ovulation in light-estrous rats induced by darkness. Endocrinologia Japonica 24, 89-96.

Wiest, W.G. (1959) Conversion of progesterone to 4pregnen-20 $\alpha$-ol-3-one by rat ovarian tissue in vitro. Journal of Biological Chemistry 234, 3115-3121.

Wiest, W.G. \& Wilcox, R.B. (1961) Purification and properties of rat ovarian $20 \alpha$-hydroxysteroid dehydrogenase. Journal of Biological Chemistry 235, 2425-2428.

Wiest, W.G., Wilcox, R.B. \& Kirschbaum, T.A. (1963) Rat ovarian $20 \alpha$-hydroxysteroid dehydrogenase: effects of estrogens and pituitary gonadotropins. Endocrinology 73, 588-595.

Wiest, W.G., Kidwell, W.R. \& Balogh, K. (1968) Progesterone catabolism in the rat ovary: a regulatory mechanism for progestation potency during pregnancy. Endocrinology 82, 844-859.

Received 24 September 1991 